\title{
Syngas conversion to higher alcohols: application of novel K-promoted coRhMo catalysts supported over carbon nanohorns and its by-products
}

\begin{abstract}
The submerged arc discharge in liquid nitrogen technique was used to synthesize carbon nanohorns (CNHs) using $90 \mathrm{~A}$ and $34 \mathrm{~V}$; generating other carbon by-products at the high temperature $(>4000 \mathrm{~K})$ plasma zone, herein depicted as: "other carbon particles" (OCP) and "other fine carbon particles" $\left(\mathrm{OCP}_{\mathrm{f}}\right)$. In the present work, a series of potassiumpromoted CoRhMo catalysts with compositions $9 \% \mathrm{~K}, 4.5 \% \mathrm{Co}, 1.5 \% \mathrm{Rh}$, and $15 \mathrm{wt} . \% \mathrm{Mo}$, respectively, were supported over these carbon nanomaterials $\left(\mathrm{CNH}, \mathrm{OCP}_{\mathrm{f}}\right.$, and $\left.\mathrm{OCP}\right)$ and characterized by BET, FTIR, RAMAN, TGA, $\mathrm{H}_{2}$-TPR, XRD, and TEM. $30 \mathrm{wt} . \% \mathrm{HNO}_{3}$ treatment at $\mathrm{T}=110^{\circ} \mathrm{C}$ under reflux conditions for 30 minutes enhanced the overall textural properties of the pristine supports and preserved their mesoporosity evidenced by the Type IV isotherms with surface area increments in the order: $\mathrm{CNH}$ (89 to 499$)>\mathrm{OCP}_{\mathrm{f}}(34$ to 82$)$ $>$ OCP $\left(10\right.$ to $\left.19 \mathrm{~m}^{2} / \mathrm{g}\right)$. The functionalized supports evidenced the presence of carboxylic acid $(-\mathrm{COOH})$ groups with the most defective sites exhibited by $\mathrm{CNHs}$ as revealed by the $\mathrm{I}_{\mathrm{D}} / \mathrm{I}_{\mathrm{G}}$ ratios ascertained by Raman spectroscopy. All three $\mathrm{KCoRhMo-supported} \mathrm{catalysts}$ prepared were thermally stable up to $400^{\circ} \mathrm{C}(\mathrm{CNH})$ and $650^{\circ} \mathrm{C}\left(\mathrm{OCP}_{\mathrm{f}}\right.$ and $\left.\mathrm{OCP}\right)$, and metals reducibility characterized by $\mathrm{H}_{2}$-TPR analysis followed the trend: $\mathrm{CNH}>\mathrm{OCP}_{\mathrm{f}}>$ OCP. Powder XRD revealed inhomogeneous particles dispersion on the OCP-supported catalyst as compared to its $\mathrm{CNH} \mathrm{\&} \mathrm{OCP}_{\mathrm{f}}$ counterparts as corroborated by the TEM analyses; probably due to significant changes in textural properties. The extensive characterization of these catalysts provided insights into their characteristic catalytic performances for the conversion of syngas to higher alcohols conducted at temperatures, pressure, GHSV, and $\mathrm{H}_{2} / \mathrm{CO}$ ratio of $300-340^{\circ} \mathrm{C}, 8.3 \mathrm{MPa}, \mathrm{GHSV}=3600 \mathrm{~mL}$ (STP) $/ \mathrm{g}_{\text {cat }}$ h, and 1.25 , respectively. CO conversion evaluated under stable reaction conditions at $340^{\circ} \mathrm{C}$ recorded a maximum of $52 \%$ for the $\mathrm{CNH}$-supported $\mathrm{KCoRhMo}$ catalysts as opposed to $38 \%$ and $25 \%$, respectively, for its $\mathrm{OCP}_{\mathrm{f}}$ and $\mathrm{OCP}$ counterparts.
\end{abstract}

Keywords: syngas conversion, higher alcohols, $\mathrm{MoS}_{2}$ catalyst, $\mathrm{CNH}, \mathrm{OCP}, \mathrm{OCP}_{\mathrm{f}}$
Volume 2 Issue I - 2017

\author{
Philip E Boahene,' Ramaswami \\ Sammynaiken, ${ }^{2}$ Ajay K Dalai' \\ 'Catalysis and Chemical Reaction Engineering Laboratories, \\ University of Saskatchewan, Canada \\ ${ }^{2}$ Saskatchewan Structural Sciences Centre, University of \\ Saskatchewan, Canada
}

Correspondence: Ajay K Dalai, Catalysis and Chemical Reaction Engineering Laboratories, University of Saskatchewan, Canada, Email ajay.dalai@usask.ca

Received: November 24, 2016 | Published: January 06, 2017
Abbreviations: HA: higher alcohols; FTS: fischer-tropsch synthesis; OCP: other carbon particles; OMC: ordered mesoporous carbon; FTIR: fourier transform infra-red; TEM: transmission emission microscopy

\section{Introduction}

Gasoline blends with up to $10 \%$ ethanol (E10) and higher alcohols are commercially available at gasoline pump stations in the USA, Canada, and some parts of Europe. ${ }^{1}$ The production of these alcohols $\left(\mathrm{C}_{2}\right.$ and $\left.\mathrm{C}_{2+}\right)$ promises immense potential to replace other additives utilized as octane boosters in automotive fuels. Catalytic conversion of synthesis gas (mainly, $\mathrm{CO}+\mathrm{H}_{2}$ ) to higher alcohols (HA) via the Fischer-Tropsch synthesis (FTS) process has received tremendous interest due to the generation of environmentally benign octane boosters and alternative fuels to supplement the diminishing supply of the world's finite fossil fuel reserves. In this regard, beneficial incentives derived from the use of these alcohols as alternative fuels or alternative fuel components in transportation systems directly tackles global climate issues such as the reduction of greenhouse gas emissions, reduction of toxic emissions, and also the improvement of the overall energy efficiency of internal combustion engines. ${ }^{2}$ Unlike gasoline and diesel fuels, higher alcohols contain oxygen components that allow gasoline-blended fuels to combust more completely; thereby, increasing the combustion efficiency and reducing air pollution, and can also be renewable resource depending on the origin of syngas feedstock (via biomass gasification). To improve selectivity and activity of these alcohol products, the catalyst metals and supports used for this reaction play a vital role. ${ }^{3}$

In the catalysis of hydrogenation reactions on heterogeneous surfaces, whereby metal precursors dispersed on a porous support act as catalyst, the support plays a crucial role due to the probable hydrogen spillover effect. ${ }^{4,5}$ The atomic hydrogen forming as a result of dissociative adsorption on the metal migrates onto the support (hydrogen spillover); making the chemical reaction proceeds not only on the metal surface but also on the support. ${ }^{5}$

In general terms, the support acts to:

a. Stabilize the active species and promoters.

b. Promote hydrogen or oxygen donation or exchange.

c. Modify the dispersion, reducibility, and electron-donating or accepting effects of metal particles ${ }^{6}$ among others.

Nevertheless, the nature of surface acidity or basicity of the support can greatly impact the surface chemistry of the final catalysts. For instance, metal oxide supports such as $\mathrm{SiO}_{2}$ and $\mathrm{Al}_{2} \mathrm{O}_{3}$ have the tendency to favour hydrocarbons formation by suppressing the reaction rate of alcohols as a result of accelerated coke deposition. ${ }^{7,8}$ 
The research findings by Concha et al. ${ }^{9}$ on the influence of different supports $\left(\mathrm{SiO}_{2}, \mathrm{Al}_{2} \mathrm{O}_{3}, \mathrm{AC}, \mathrm{CeO}_{2}\right)$ on reduced and sulfided Mo-based catalysts for the hydrogenation of $\mathrm{CO}$ concluded that minimum hydrocarbon selectivity was observed on the AC-supported catalyst as compared to its metal oxide counterparts. A study conducted by Iranmahboob et al. ${ }^{10}$ concluded that linear alcohols were mainly observed on the AC-supported $\mathrm{K}_{2} \mathrm{CO}_{3} / \mathrm{CoS} / \mathrm{MoS}_{2}$ catalyst for syngas conversion to alcohols. ${ }^{10}$ Also, Surisetty et al. ${ }^{11}$ reported a space time yield and total alcohols selectivity of $0.296 \mathrm{~g} /(\mathrm{g}$ of cat./h) and $35.6 \%$, respectively, for their trimetallic $\mathrm{K}-\mathrm{Co}-\mathrm{Rh}-\mathrm{Mo} / \mathrm{MWCNT}$ catalyst compared to the AC-supported counterpart at similar metal loadings. ${ }^{11}$ Furthermore, in our previous investigation of largepore ordered mesoporous carbon (OMC)-supported KCoRhMo catalyst and their application for the HAS reaction, it was observed that though the products selectivities was fairly comparable to its MWCNT counterpart at similar metal loadings, XRD analysis of the former catalysts evidenced better homogeneous species dispersion on former support. This observation was attributed to the enhanced textural properties of the OMC-supported catalyst, which exhibited comparative catalytic performance as its MWCNT counterpart at higher metal loadings.

Though MWCNT and OMC have proven tendencies to produce alcohols, our present research has observed that carbon in the form of carbon nanohorns $(\mathrm{CNH})$ can be a superior catalyst supports for syngas conversion applications. Single-wall carbon nanohorn (SWCNH) is one of the most attractive new forms of nanocarbons. ${ }^{12}$ These carbon nanoparticles was discovered by Iijima et al. ${ }^{12}$ in 1999 and constitutes a form of single-walled carbon nanostructures with graphitic tubes and cone-shaped caps, forming a cone angle of $20^{\circ}$ at one end and individual SWCNH particles typically aggregating to form a spherical structure with diameters of $50-90 \mathrm{~nm}$. Depending on the synthesis conditions, $\mathrm{CNH}$ aggregates can be one of four different types: dahlia-like, ${ }^{12-14}$ bud-like, ${ }^{13}$ petal-like, ${ }^{14}$ or seed-like. ${ }^{15}$ For instance, whereas carbon nanohorns aggregates to form spherelike matrix under synthesis conditions, carbon nanotubes on the other hand has been found to aggregate to form bundles of cylindrical nanotubules along the long axes of the nanotubes. ${ }^{12-15}$ Properties, such as high surface area, high thermal stability, high purity, and conductive graphitic structures provide $\mathrm{CNHs}$ with specific properties that enable numerous potential applications, such as adsorbents, molecular sieves catalyst supports, among others. ${ }^{16-18}$

This family of carbon nanohorns and its by products synthesized by the novel submerged arc in liquid nitrogen technique were investigated as potential catalyst supports due to their diverse porous structure, resistance to acidic and basic environments, easy accessibility to their internal surface area, easy modification of their surface chemistry among other advantages. Despite the fact that this novel porous carbon material $(\mathrm{CNH})$ has recently attracted significant importance in the field of heterogeneous catalysis, to the best of our knowledge, no work has yet been reported on $\mathrm{CO}$ hydrogenation reaction over these supports for higher alcohols synthesis. That notwithstanding, $\mathrm{CNH}-$ supported NiMo catalysts proved successful in the hydrogenation of petroleum feedstock in hydrotreating reactions. ${ }^{19}$ Thus, the motivation of the present work was to explore the potential catalytic applications of $\mathrm{CNH}$ and its by-products $\left(\mathrm{OCP}_{\mathrm{f}}\right.$ and $\left.\mathrm{OCP}\right)$ supports for higher alcohols synthesis via syngas conversion in a laboratory fixed bed reactor under industrial conditions and evaluate its performance with the known MWCNT counterpart at similar metals loading.

\section{Experimental \\ $\mathrm{CNH}$ synthesis, preparation of $\mathrm{CNH}, \mathrm{OCP}_{\mathrm{f}}$ and $\mathrm{OCP}$ - supported KCoRhMo catalysts}

The pristine supports $\left(\mathrm{CNH}, \mathrm{OCP}_{\mathrm{f}}\right.$ and $\left.\mathrm{OCP}\right)$ were synthesized by the submerged arc discharge in liquid nitrogen technique described elsewhere, ${ }^{20}$ at a fixed current of $90 \mathrm{~A}$ and $34 \mathrm{~V}$. Surface modification of as-made $\mathrm{CNH}$ and its by-products $\left(\mathrm{OCP}_{\mathrm{f}}\right.$ and $\left.\mathrm{OCP}\right)$ were achieved by using $7 \mathrm{M} \mathrm{HNO}_{3}$ at $110^{\circ} \mathrm{C}$ under reflux condition for $30 \mathrm{~min}$, filtered, thoroughly rinsed with de-ionized water until a neutral $\mathrm{pH}$, and then dried overnight prior to particles separation and supports alkalinisation with the required amount of aqueous solution of $\mathrm{K}_{2} \mathrm{CO}_{3}$. This was followed by supports stabilization at $300^{\circ} \mathrm{C}$ in argon flow of $50 \mathrm{~mL} / \mathrm{min}$ at a heating rate of $10^{\circ} \mathrm{C} / \mathrm{min}$ for $4 \mathrm{~h}$, and consequently, the co-impregnation of respective metal $(\mathrm{Co}, \mathrm{Mo}, \mathrm{Rh})$ species using ammonium heptamolybdate tetra hydrate (Alfa-Aesar, Canada), potassium carbonate (Sigma-Aldrich, Canada), cobalt acetate tetra hydrate (Alfa-Aesar, Canada), and rhodium chloride hydrate (SigmaAldrich, Canada) as precursors for $\mathrm{Mo}, \mathrm{K}, \mathrm{Co}$, and $\mathrm{Rh}$, respectively. The oxidic form of the dried powder K-doped CoRhMo samples were obtained after $4 \mathrm{~h}$ of oven drying at $120^{\circ} \mathrm{C}$, followed by stabilization at $450^{\circ} \mathrm{C}$ under argon flow of $50 \mathrm{~mL} / \mathrm{min}$ at a heating rate of $10^{\circ} \mathrm{C} /$ $\min$ for $12 \mathrm{~h}$. The final catalyst composition (wt.\%) of $9 \% \mathrm{~K}, 15 \% \mathrm{Mo}$, $4.5 \% \mathrm{Co}$ and $1.5 \% \mathrm{Rh}$, respectively, is to be attained. Henceforth, the fine powder form of the $\mathrm{CNH}, \mathrm{OCP}_{\mathrm{f}}$ and $\mathrm{OCP}$-supported $\mathrm{KCoRhMo}$ catalyst samples are designated as Cat-CNH, Cat- $\mathrm{OCP}_{\mathrm{f}}$ and Cat-OCP, respectively. The feedstock used in this study was the commercially available syngas mixture procured from Praxair, Canada.

\section{Characterization of supports and catalysts}

Textural properties (specific surface area, pore volume, and average pore diameter) of all the carbon supports and prepared catalysts were determined using the $\mathrm{N}_{2}$-adsorption/desorption technique measured on a Micromeritics ASAP 2020 analyzer at liquid nitrogen temperature of $77 \mathrm{~K}$. Detailed description of the procedure can be found in the literature. $^{7}$

Laser Raman analyses of the carbon supports were carried out using a Raman imaging equipment (RenishawInvia Raman Microscope) running WiRE software - version 1.3, with the following pre-set parameters to determine the quality of carbon structure: wave length of laser excitation, $\lambda=514 \mathrm{~nm}$, laser power $=\sim 1 \mathrm{~mW}$, exposure time $=30 \mathrm{~s}$, microscope objective $=50$, and $1800 \mathrm{l} / \mathrm{mm}$ grating.

Fourier transform infra-red (FTIR) spectra were recorded in the range 400-4000 $\mathrm{cm}^{-1}$ wave numbers with a JASCO FT-IR 4100 using pellets prepared with spectroscopic grade potassium bromide $(\mathrm{KBr})$. Surface functional groups present on the catalyst samples were qualitatively determined by this technique using 32 scans with a nominal resolution of $4 \mathrm{~cm}^{-1}$.

Transmission Emission Microscopy (TEM) was used to study the morphological features of the support and catalysts. Electron micrographs were obtained using a JEOL 2011 scanning transmission electron microscope equipped with Gatan Imaging Filter (GIF 2000) to facilitate imaging at $200 \mathrm{keV}$ using low to high magnifications, in the range of 20-500k times magnification. Prior to sample analysis, the powder samples were sonicated in ethanol using an ultrasonic bath for $1 \mathrm{~h}$, followed by deposition of the resultant solution on a 200 mesh carbon-coated copper grid. 
Wide-angle X-ray diffraction patterns of the powder catalyst samples were recorded on a Rigakudiffracto meter using high intensity $\mathrm{Cu} \mathrm{K} \alpha$ radiation source $(\lambda=0.1541 \mathrm{~nm})$. Scanning of each sample was performed at a rate of $0.05^{\circ} \mathrm{s}$ within a $2 \theta$ range of 10 to $80^{\circ}$. The phases present were identified using the JCPDS diffraction files by matching the corresponding diffraction peaks or patterns.

The $\mathrm{H}_{2}$-TPR profiles of the catalysts were performed in order to study the reducibility of the metal species in the catalysts. The stabilized catalyst sample $(0.2 \mathrm{~g})$ was first purged in a flow of argon at $170^{\circ} \mathrm{C}$ to remove traces of water, and then cooled to $40^{\circ} \mathrm{C}$. Then the TPR of each sample was performed using $3.1 \% \mathrm{H}_{2}$ in $\mathrm{He}$ gas stream at a flow rate of $30 \mathrm{~mL} / \mathrm{min}$ at atmospheric pressure using an automated Quanta chrome gas sorption instrument (AUTOSORB IQ TPD-TPR analyzer) equipped with a thermal conductivity detector, heating at a linearly programmed rate of $10^{\circ} \mathrm{C} / \mathrm{min}$ up to $700^{\circ} \mathrm{C}$. The amount of chemisorbed hydrogen was measured using the AUTOSORB IQ TPD-TPR analyzer system. The stabilized catalyst sample $(0.2 \mathrm{~g})$ was first purged in a flow of argon at $170^{\circ} \mathrm{C}$ to remove traces of water. The temperature was then raised to $700^{\circ} \mathrm{C}$ at a linearly programmed rate of $10^{\circ} \mathrm{C} / \mathrm{min}$ and the temperature reduction profiles of the catalyst samples recorded.

\section{Catalytic activity}

The feedstock used in this study was the commercially available syngas mixture procured from Praxair, Saskatoon, Canada. The CO conversion and selectivity of desired products for the catalysts studied were evaluated using the as-received syngas composition $(50 \%$ $\mathrm{H}_{2}: 40 \% \mathrm{CO}: 10 \% \mathrm{Ar}$ ). Higher alcohol synthesis experiments were conducted in a single-pass downward flow fixed bed reactor system (22 mm ID; $450 \mathrm{~mm}$ length) made of Inconel. ${ }^{18}$ In brief, approximately $2 \mathrm{~g}$ of catalyst was diluted with $12 \mathrm{~mL}$ of 90 mesh size silicon carbide particles as diluents so as to enhance heat and mass transfer along the length of the reactor. An initial sulfidation/reduction of the oxidic catalyst was necessary prior to catalytic activity study. This was accomplished by first pressurizing the reactor to $3.44 \mathrm{MPa}(500 \mathrm{psig})$ with helium followed by sulfidation/reduction at $4500^{\circ} \mathrm{C}$ (rate of $20^{\circ} \mathrm{C}$ $/ \mathrm{min}$ ) for $6 \mathrm{~h}$ using a gas mixture containing $10 \mathrm{~mol} \% \mathrm{H}_{2} \mathrm{~S}$ (balance $\mathrm{H}_{2}$ ) at a flow rate of $50 \mathrm{~mL} / \mathrm{min}$. The temperature was then lowered to the reaction temperature and the system pressurized to the reaction conditions. The synthesis gas mixture was then introduced via mass flow controllers and the higher alcohols synthesis reaction conducted under steady-state at reaction conditions of $300-3400^{\circ} \mathrm{C}, 8.3 \mathrm{MPa}$ (1300 psig), and a gas hourly space velocity (GHSV) of $3.6 \mathrm{~m}^{3}$ (STP)/ ( $\mathrm{h} \mathrm{kg}_{\text {cat }}$ ) over a period of $24 \mathrm{~h}$. The product gas was cooled to $00^{\circ} \mathrm{C}$ in a cold trap to separate it into gaseous and liquid phases at the reaction pressure..$^{7,21}$

The $\mathrm{CO}$ conversion and other gaseous products were monitored hourly by venting the exit gas through an online Shimadzu gas chromatograph instrument equipped with an integrated thermal conductivity detector (TCD) via a sampling valve. Using Ar as an internal standard, the $\mathrm{CO}$ conversion was calculated and the overall mass balance of the reaction was determined. The liquid products were collected after $24 \mathrm{~h}$ reaction period and analyzed with a Varian 3400 gas chromatograph equipped with a Stabil Wax capillary column and a flame ionization detector (FID). The volume and weight of liquid products were measured to check the mass balance. The experiments were repeated at least twice to check reproducibility and to confirm that the results obtained were within the experimental error of $3 \% .^{21}$

\section{Results and discussion}

\section{Support and catalyst characterizations}

$\mathbf{N}_{2}$-adsorption/desorption measurement: Measurements of textural properties of the supports and catalysts were conducted by the nitrogen adsorption/desorption technique performed at liquid nitrogen temperature of $-196^{\circ} \mathrm{C} .{ }^{22}$ Figure 1A shows the isotherms of the three pristine supports $\left(\mathrm{CNH}, \mathrm{OCP}_{\mathrm{f}}\right.$ and $\left.\mathrm{OCP}\right)$ as well as their respective $\mathrm{HNO}_{3}$-treated counterparts. Similar isotherms are displayed for the corresponding supported catalysts as depicted in Figure 1B. The existence of textural mesoporosity is clearly observable from the profiles of the pristine and $\mathrm{HNO}_{3}$ treated supports, as well as their respective supported $\mathrm{KCoRhMo} \mathrm{catalysts.} \mathrm{The} \mathrm{type} \mathrm{IV} \mathrm{isotherms}$ with $\mathrm{H} 1$ hysteresis loop was confirmed ${ }^{23,24}$ and can be observed in all catalysts, corroborating the evidence of textural mesoporosity in the final catalysts, which is crucial for catalytic reactions. It is clear from Figure 1B that the isotherms exhibited by all catalysts showed a slight change in the shape of the hysteresis loops of the supports as a result of metals loading. This indicates that all supported catalysts exhibited uniform textural porosity, which is also in agreement with $\mathrm{XRD}$ results. It is known in heterogeneous catalytic reactions that reactants predominantly react on the surface of the catalyst; giving an indication of the important role structural porosity of the catalyst plays in controlling mass transfer processes via species diffusion in such reactions. Table 1 gives a summary of the textural properties of the pristine $\mathrm{CNH}, \mathrm{OCP}_{\mathrm{f}}, \mathrm{OCP}$ supports and their respective functionalized forms as well as the supported KCoRhMo catalysts. It is worth mentioning that $\mathrm{HNO}_{3}$ pre-treatment of pristine carbon materials such as MWCNTs resulted in the opening of the closed ends and caps of the pristine material and also significantly improved its textural properties..$^{25}$ Similarly, for the $\mathrm{CNH}$ and it's by products studied, nitric acid treatments of the pristine supports resulted in increase in surface area and pore volume. Wang et al..$^{20}$ observed increased surface areas of their SWCNH material following an oxidization treatment by heating in air at $200^{\circ} \mathrm{C}$ for several hours. The observed increment in surface area was attributed to the incorporation of openings in individual nanohorns that enhance the creation of reactive adsorption sites. ${ }^{20}$ A similar phenomenon may have occurred during the $\mathrm{HNO}_{3}$ treatments of the pristine carbon materials in our case. However, a decrease in pore diameters of the functionalized supports as observed in Table 1 can be attributed to the probable narrowing of the average internal pore diameter of the carbon materials due to the accumulation of various oxygen containing functional groups occupying the interior surfaces within the supports. The $\mathrm{CNH}$ functionalized support (Fun$\mathrm{CNH}$ ) showed the highest surface area, pore volume as well as pore diameter, while the OCP functionalized support (Fun-OCP) recorded the least values of the parameters. This suggests that significant etching effect occurred in the pristine $\mathrm{CNH}$ material as compared to its $\mathrm{OCP}_{\mathrm{f}}$ and $\mathrm{OCP}$ counterparts. The corresponding catalysts resulting from similar metals loading $(9 \% \mathrm{~K}, 4.5 \% \mathrm{Co}, 1.5 \% \mathrm{Rh}$, and $15 \% \mathrm{Mo})$ on the respective functionalized supports showed decrease in surface area and pore volumes, following the order: Cat-CNH $>$ Cat- $\mathrm{OCP}_{\mathrm{f}}>$ Cat-OCP; however, changes in the pore diameter of the catalysts did not follow a particular trend. The monotonic reduction in textural properties (specific surface area and pore volume) of the supports as a result of metal $(\mathrm{Co}, \mathrm{Rh}, \mathrm{Mo})$ precursors loading was expected. Nonetheless, the decrease in specific surface area as a result of coimpregnation of $\mathrm{Co}, \mathrm{Mo}$, and Rh metal precursors on the supports also significantly influenced the homogeneity of dispersed metal species 
on the surface of the supports, as corroborated by the X-ray powder diffraction analysis. ${ }^{7,21}$ Furthermore, a similar trend (as illustrated above) can be observed when the normalized specific BET surface area $\left(\mathrm{NS}_{\mathrm{BET}}\right)$ of the prepared catalysts were computed Table 1 using the equation proposed by Vradman et al. ${ }^{26}$

$$
N S_{B E T}=\frac{\left(S_{B E T}\right)_{C a t}}{(1-x) \cdot\left(S_{B E T}\right)_{S u p}}
$$

Where $\mathrm{NS}_{\mathrm{BET}}$ is the normalized $\mathrm{S}_{\mathrm{BET}}$ and $\mathrm{x}$ is the weight fraction of the phases. One can deduce from the computed $\mathrm{NS}_{\mathrm{BET}}$ values that Cat-OCP suffered the most pore blockage as compared to Cats-CNH and $\mathrm{OCP}_{\mathrm{f}}$; suggesting that while the introduction of the oxidic metal nanoparticles caused a minimal reduction in pore volume for the $\mathrm{CNH}$ and $\mathrm{OCP}_{f}$ catalysts (probably due to their higher surface areas), the CatOCP experienced quite a high reduction in pore volume. Moreover, these results also give an indication that impregnation of metal species on a catalyst support plays a vital role in the overall catalytic surface area required for a given chemical reaction and affected differently the porosity as well as the overall textural properties of the final catalysts investigated. Thus, the activity and alcohol products selectivities could be affected by the available surface areas of the respective catalysts during the surface-catalyzed HAS reaction.

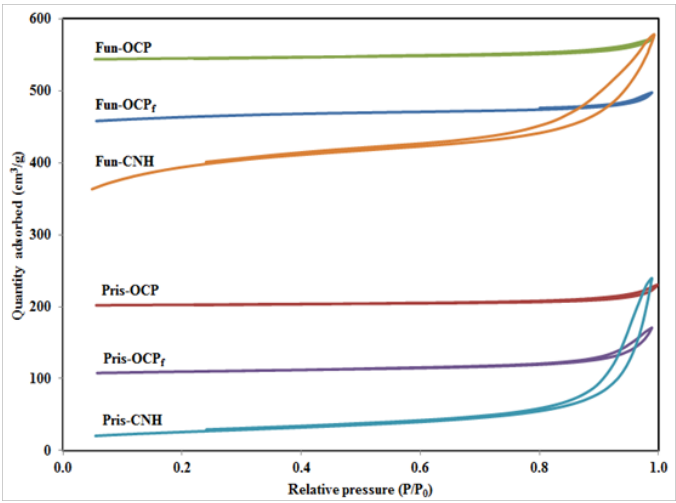

Table I Textural properties of $\mathrm{CNH}, \mathrm{OCP}$, OCP supports \& supported KCoRhMo catalysts

\begin{tabular}{|c|c|c|c|c|}
\hline Sample ID & $\begin{array}{l}\text { SSA } \\
\left(\mathrm{m}^{2} / \mathrm{g}\right)\end{array}$ & $\begin{array}{l}\text { PV } \\
\left(\mathrm{cm}^{3} \cdot \mathrm{g}\right)\end{array}$ & $\begin{array}{l}\text { II_I I I,,d, } \\
\text { (urn) }\end{array}$ & 'MEET \\
\hline \multicolumn{5}{|l|}{ SUPPORTS } \\
\hline Pris-CNH & 89 & 0.34 & 18.5 & \\
\hline Pris- $\mathrm{OCP}_{f}$ & 34 & 0.1 & 14.6 & \\
\hline Pris-OCP & 10 & 0_03 & 13_9 & \\
\hline Fun-CNH & 499 & OA 9 & 9.5 & \\
\hline Fun- $\mathrm{OCP}_{f}$ & 82 & 0_II & $6 \_7$ & \\
\hline Fun-OCP & 19 & 0.05 & 9.2 & \\
\hline \multicolumn{5}{|l|}{ Catalysts } \\
\hline $\mathrm{Cat}-\mathrm{CIVH}$ & 322 & 0.27 & 8.6 & 0.92 \\
\hline Cat-OCP ${ }_{f}$ & 42 & 0.06 & 9.3 & 0.74 \\
\hline Ca t-O CP & 9 & 0_03 & 8_9 & 0_70 \\
\hline
\end{tabular}

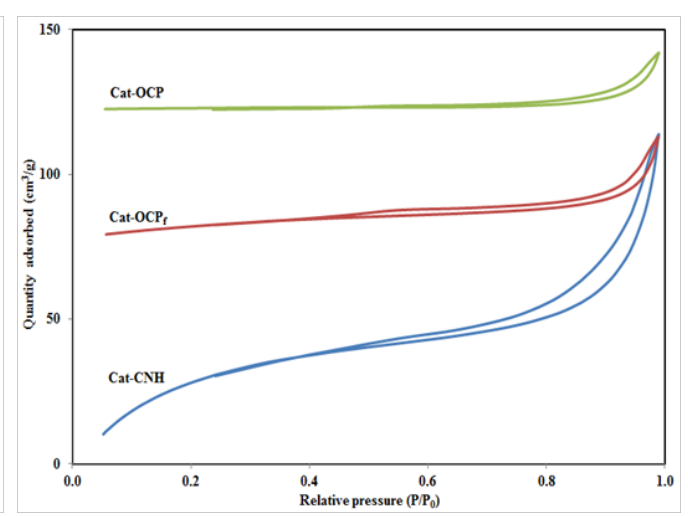

Figure IA $\mathrm{N}_{2}$-adsorption isotherms of pristine $\mathrm{CNH}_{1}, \mathrm{OCP}_{f}$ \& $\mathrm{OCP}$ supports as well as their functionalized forms.

Figure I B $\mathrm{N}_{2}$-adsorption isotherms of $\mathrm{CNH}, \mathrm{OCP}_{f}$ \& OCP-supported $\mathrm{KCoMoRh}$ catalysts.

Wide-angle X-ray diffraction: X-ray diffraction (XRD) patterns of the pristine $\mathrm{CNH}$ as well as the $\mathrm{KCoRhMo}$ catalysts samples supported on the functionalized $\mathrm{CNH}, \mathrm{OCP}_{\mathrm{f}}$, and $\mathrm{OCP}$ supports were recorded for $2 \theta$ values in the range of $10-80^{\circ}$ and are shown in Figure 2. Profiles of the generated XRD peaks of these samples were analyzed and matched up with the corresponding peaks using the JCPDS chemical spectra data bank. ${ }^{27-29}$ From Figure 2, a sharp peak at two theta degree of approximately 26 can be observed for Cat-CNH and is representative of a graphite (002) framework. ${ }^{19}$ The existence of two other graphitic broad peaks were also confirmed at two theta degrees of $42(100)$ and 44 (101). The presence of graphite is attributed to the single-layer graphitic wall which encompasses CNHs. This feature was present in all samples, suggesting that all three samples have remnants of $\mathrm{CNH}$ present in them. Similarly, peaks occurring at $2 \theta$ of 20.5, $30.4,36.8$ and $40.6^{\circ}$ can be attributed to the crystalline $\mathrm{MoO}_{3}$. These crystalline phases were less on the $\mathrm{CNH}$-supported catalyst, giving an indication of the uniform dispersion of nanoparticles on this support. This could be explained due to the relatively lower surface area (19 $\mathrm{m}^{2} / \mathrm{g}$ ) of Cat-OCP as opposed to 499 and $82 \mathrm{~m}^{2} / \mathrm{g}$ for Cats-CNH and $\mathrm{OCP}_{\mathrm{f}}$, respectively. It is noteworthy that a catalyst support with more desirable textural properties would better enhance the stabilization the active species and promoters as well as play a vital role to modify the dispersion, reducibility, and electron-donating or accepting effects of metal nanoparticles [30]. Consequently, the relatively higher surface area of the Fun-CNH support may have played a significant role by enhancing great dispersion of catalytic phases as confirmed by the $\mathrm{XRD}$ profile for its corresponding catalyst. Also, the peaks occurring at $2 \theta$ values of $26.2,28.3$ and 34.8 can be assigned to the presence of $\mathrm{K}_{2} \mathrm{Mo}_{2} \mathrm{O}_{7}$ species in the samples..$^{21,31}$ The average $\mathrm{MoO}_{3}$ crystallite size from the full width at half maximum (FWHM) diffraction profile computed by the Debye-Scherer's equation $(L=0.9 \lambda / \beta \cos \theta)$ for both Cats-CNH and $\mathrm{OCP}_{\mathrm{f}}$, showed $\mathrm{MoO}_{3}$ crystallite size in the range 6-10 $\mathrm{nm}$ as opposed to $16 \mathrm{~nm}$ for the Cat-OCP catalyst; giving an indication that there must have been metal species agglomeration on the latter catalyst due to its lower specific surface area. Nonetheless, all these particle sizes quite favoured the higher alcohols synthesis reaction, though a much lower extent for Cat-OCP. Moreover, it should be pointed out that these nanoparticles may experience significant phase changes as a result of time-on-stream during higher alcohol synthesis reaction under prevailing operation conditions. 


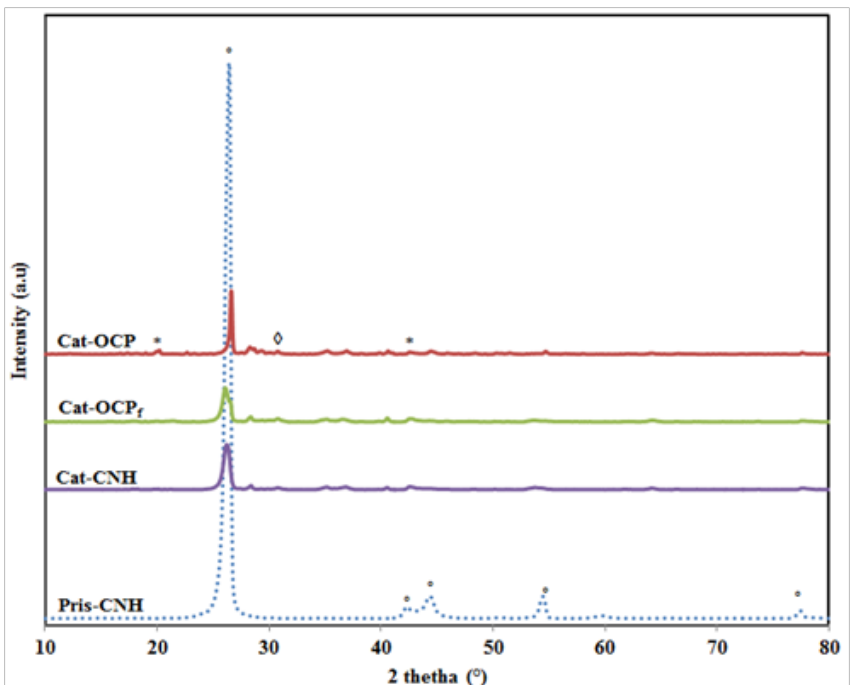

Figure 2 XRD profiles for $\mathrm{CNH}, \mathrm{OCP} \&$ OCP-supported KCoRhMo catalysts.

Raman spectroscopic analysis: To effectively ascertain the slight changes occurring in the orientation of the carbon-carbon bonds as a result of an interaction of light with the carbon nanomaterials analysed, the highly sensitive vibrational spectroscopic technique, Raman spectroscopy, was used. ${ }^{32}$ Raman spectroscopic analysis is a non-destructive technique and particularly well suited to detect small changes in structural morphology of carbon nanomaterials. ${ }^{33}$ Every band occurring in the Raman spectrum corresponds directly to a specific vibrational frequency of a bond within the molecules of the specimen investigated. ${ }^{34}$ For carbon materials such as graphite, carbon nanotubes, ordered mesoporous carbons, carbon nanohorns, etc., information such as electronic structure as well as sample imperfections can be derived from spectra obtained from this technique. ${ }^{21,35}$ Figures 3A, 3B show the Raman profiles of both the pristine and functionalized supports as well as their corresponding KCoMoRh catalysts. From the Raman spectra, the two distinct peaks in the range of $1340-1350 \mathrm{~cm}^{-1}$ and $1580-1595 \mathrm{~cm}^{-1}$ observed can be attributed to the so called D- and G-bands, respectively. ${ }^{19-20}$ The former is characteristic of the extent of disorderliness in the carbon matrix and the latter is due to the $\mathrm{C}-\mathrm{C}$ stretching modes present in the material. While the G-band indicates the graphitic E2g plane vibration, the D-band is due to the disordered parts such as grain boundaries, ${ }^{21,36}$ which is indicative of the Alg plane. It is known that the intensity ratio of the $D$ to $G$ bands $\left(I_{D} / I_{G}\right)$ is generally used to denote the extent of disorderliness present in the graphite layer of carbon material. The greater the value of this parameter, the more disordered the material becomes. ${ }^{37}$ For the catalysts studied, it is clear from Figure 3B that the OCP-supported KCoRhMo catalyst exhibited the least $\mathrm{I}_{\mathrm{D}} / \mathrm{I}_{\mathrm{G}}$ ratio, which is indicative of the existence of lesser defective sites for the HAS reaction as compared to the $\mathrm{OCP}$ and $\mathrm{CNH}$-supported catalysts. The computed $\mathrm{I}_{\mathrm{D}} / \mathrm{I}_{\mathrm{G}}$ ratios for the supported-catalysts followed the order: Cat-CNH (1.36) $>$ Cat-OCP $(0.74)>$ Cat-OCP $(0.51)$, which corroborates the observed trend. Also, it can be noticed that for all catalysts samples studied, the line width of the G mode is narrower than that of the $\mathrm{D}$ band, confirming that the $\mathrm{G}$ mode is related to the crystalline component in carbons. ${ }^{32}$ Moreover, the bandwidth of the D mode is clearly greater for the Cat-OC Pas compared to Cats-CNH and $\mathrm{OCP}_{\mathrm{f}}$; giving an indication that of less ordering in the former samples than that of latter. It can also be noted from Figure 3B that other peaks located at 261, 540, 789, 904, 967, and $1080 \mathrm{~cm}^{-1}$ existed in the Raman spectra of the catalyst samples studied and can be attributed to metaloxygen species formation, probably of the forms; O-Mo-O, K-Mo-O, and Co-Mo-O, bonds.
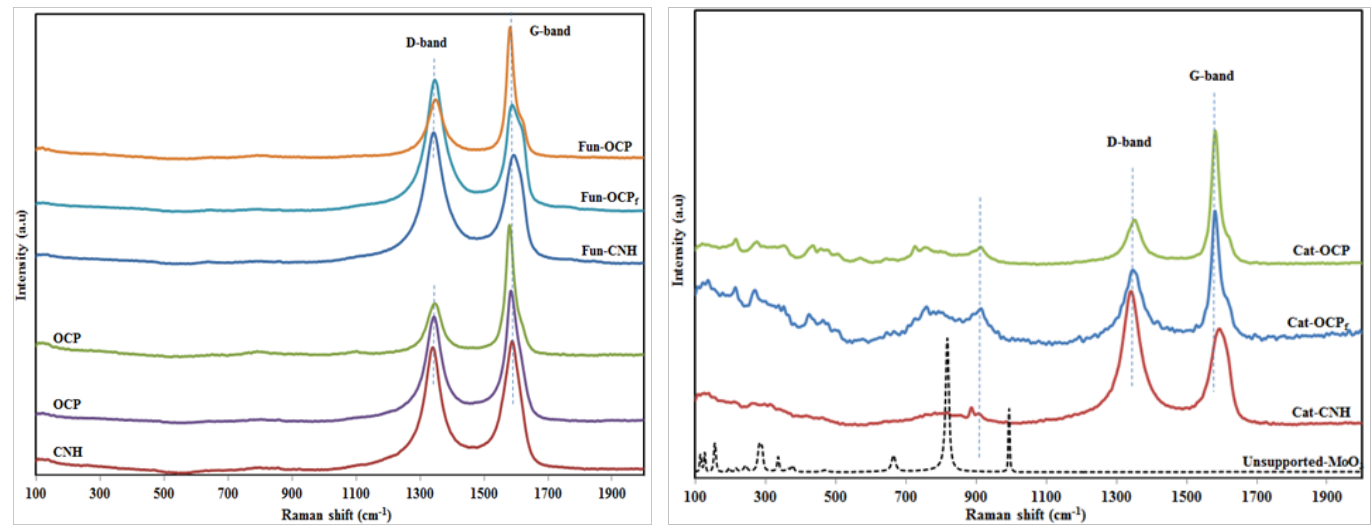

Figure 3A Raman spectra of pristine $\mathrm{CNH}, \mathrm{OCP}_{f}$ \& $\mathrm{OCP}$ as well as their functionalized supports

Figure 3B Raman spectra for $\mathrm{CNH}, \mathrm{OCP}_{f} \& \mathrm{OCP}$-supported $\mathrm{KCoRhMo} \mathrm{catalysts}$

Fourier transform infra-red analysis: The surface functional groups present in all the carbon materials studied were analyzed by the FTIR technique and are shown in Figures 4A, B. The spectra of functionalized samples as shown in Figure 4A evidenced an additional $-\mathrm{C}=\mathrm{O}$ band emerging at $1,719 \mathrm{~cm}^{-1}$, which is attributed to the stretching vibration in carboxyl, ketones and aldehydes groups. ${ }^{38,39}$ It is noteworthy to mention that these carboxylic groups can be generated due to the oxidation of some carbon atoms on the surface of the carbon supports $\left(\mathrm{CNH}, \mathrm{OCP}_{\mathrm{f}} \& \mathrm{OCP}\right)$ as a result of the $\mathrm{HNO}_{3}$ pretreatment. ${ }^{21}$ The FTIR spectra also show a broad band centered at 3,450 $\mathrm{cm}^{-1}$ which signifies phenolic $\mathrm{O}-\mathrm{H}$ stretching vibrations. ${ }^{19}$ The band at $1233 \mathrm{~cm}^{-1}$ can be assigned to contributions from stretching C-O-C vibrations (in ether and lactone structures or other single bonded oxo-group, C-O-R). ${ }^{40}$ The presence of carboxylic acid groups on the surfaces of functionalized supports $\left(\mathrm{CNH}, \mathrm{OCP}_{\mathrm{f}} \& \mathrm{OCP}\right)$ is evidence of the introduction of oxygenated functional groups at the defect sites of the pristine materials. Furthermore, an additional prominent peak occurring at $1575 \mathrm{~cm}^{-1}$ on the spectrum of Fun-CNH can be assigned to stretching vibrations (asymmetric and symmetric, respectively) of nitro group $\left(\mathrm{NO}_{2}\right)$, indicating the simultaneous occurrence of nitration 
reactions during the intended $\mathrm{HNO}_{3}$ chemical oxidation treatment. ${ }^{41}$ This peak was absent in the spectra of Fun-OCP $\mathrm{F}_{\mathrm{f}}$ and Fun-OCP supports; suggesting that the chemical composition of the carbon network in the $\mathrm{CHN}$ support undergoes a more considerable change during oxidation with nitric acid as compared to its $\mathrm{OCP}_{\mathrm{f}}$ and OCP counterparts. This observation provides insight into the fact that for same functionalizing agent and under similar treatment conditions, the nature of carbon material will be impacted differently by the nitric

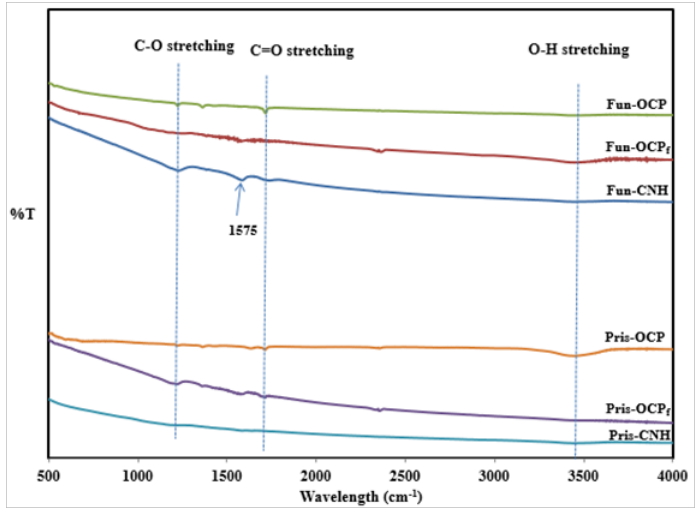

acid treatment. From Figure 4B, it can be observed that most of the peaks disappeared due to their consumption in metal-oxygen bond formation, following metal precursor impregnation and subsequent calcination in $\mathrm{N}_{2}$ atmosphere. All catalysts showed peaks at 866 and $969 \mathrm{~cm}^{-1}$, which could be ascribed to out-of-plane deformation of C-H bonds ${ }^{40,41}$ possibly via the formation of metal species moiety. These metal-oxygen bands were absent in all pristine and functionalized supports.

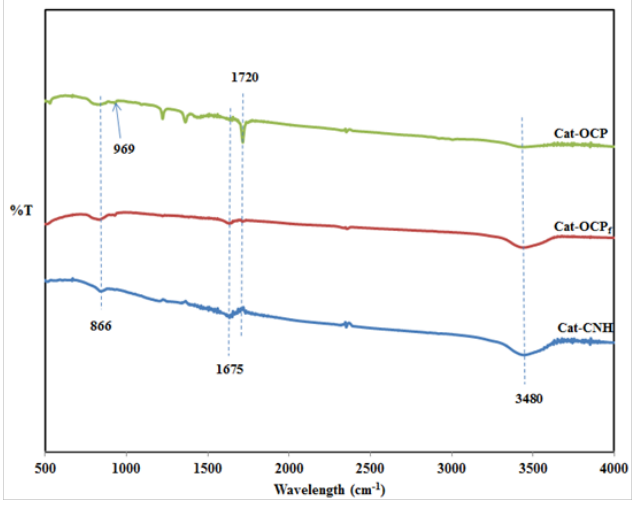

Figure 4A FTIR profiles of pristine $\mathrm{CNH}, \mathrm{OCP}_{\mathrm{f}} \& \mathrm{OCP}$ as well as their functionalized supports.

Figure 4B FTIR profiles for $\mathrm{CNH}, \mathrm{OCP}_{\mathrm{f}}$ \& $\mathrm{OCP}$-supported $\mathrm{KCoRhMo} \mathrm{catalysts.}$

Thermogravimetric analysis: The thermogravimetric (TG) technique was used to determine the percent weight loss of the catalyst samples as a function of temperature so as to gain insight of the thermal stability of the carbon-supported KCoRhMo catalysts during the HAS reaction. Figure 5 shows the TGA profiles for the catalysts investigated. Typically, carbon-supported catalysts have the propensity to undergo significant weight loss during chemical reactions in the presence of temperature..$^{42}$ This weight loss is commonly associated with the evolution of gaseous species, which can be quantifiable if the TGA setup used for analysis is equipped with mass spectrometer (MS). For instance, it has been reported that within the range of temperature for the TG analysis $\left(150-700^{\circ} \mathrm{C}\right)$ for typical carbon materials, a significant amount of $\mathrm{CO}_{2}$ (resulting from the decomposition of carboxyl groups) together with other compounds such as methane, butane and butanol (resulting from the decomposition of the carbon framework) have been observed in the MS traces..$^{40}$ At low-temperature, $\mathrm{CO}_{2}$ evolution may be the result of decomposition of carboxyl groups; however, at high-temperature, the decomposition of anhydride and lactone groups have been reported..$^{43}$ Moreover, whereas $\mathrm{CO}_{2}$ evolution mostly occurs below $500^{\circ} \mathrm{C}$ and $\mathrm{CO}$ evolution proceeding above this temperature, both physisorbed and chemisorbed water are mostly released in the range of $100-450{ }^{\circ} \mathrm{C} .{ }^{44,45}$ However, in the present work, quantitative evaluation of the corresponding evolved gaseous species was not determined. Nonetheless, the corresponding $\%$ mass loss for the supported catalysts investigated in the temperature range of 200$500^{\circ} \mathrm{C}$ followed the trend: Cat-CNH $(9.4 \%)>\mathrm{Cat}^{-\mathrm{OCP}_{\mathrm{f}}}(1.4 \%)>\mathrm{Cat}-$ OCP $(0.9 \%)$. According to the observed trend, Cats-OCPf and OCP exhibited better thermal stability properties as compared Cat-CNH; however, the latter catalyst would still survive the practical HAS reaction conditions since the actual HAS reaction does not go beyond $400^{\circ} \mathrm{C}$. One could also deduce from the above trend and Figure 5 that significant weight loss as a function of temperature for the Cat-CNH suggests a form of decomposition of chemical species in this material as temperature gradually increased; resulting in the generation of their unique defective sites that favoured the HAS reaction.

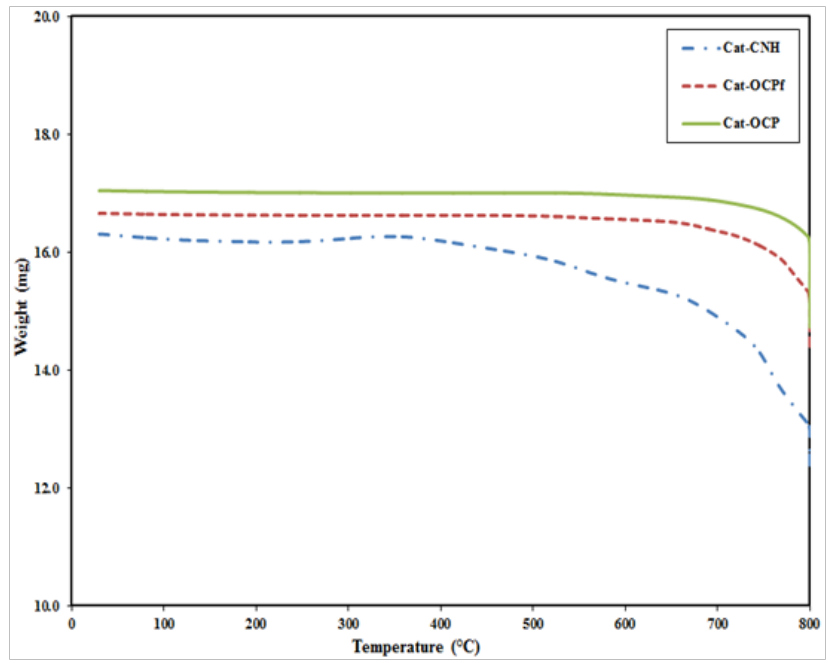

Figure 5 TGA profiles for $\mathrm{CNH}_{,} \mathrm{OCP}_{f} \&$ OCP-supported $\mathrm{KCoRhMo} \mathrm{catalysts.}$

Temperature programmed reduction analysis: The reducibility of metal species in the catalysts was ascertained by the temperature programmed reduction (TPR) technique using hydrogen gas as the probe gas. As can be seen in the displayed $\mathrm{H}_{2}$-TPR profiles in Figure 6, all three KCoRhMo supported catalysts studied evidenced the typical two-step hydrogen consumption peaks associated with molybdenumsupported catalysts. The first step involved the reduction of octahedrally coordinated $\mathrm{MoO}_{3}$ species $\left(\mathrm{Mo}^{6+}\right)$ to its tetrahedral $\mathrm{MoO}_{2}$ forms $\left(\mathrm{Mo}^{4+}\right)$, which undergoes further reduction to lower oxidation state molybdate moieties in the second step at higher temperatures. ${ }^{46}$ From the TPR profiles, four main peaks were observed to occur at $135^{\circ} \mathrm{C} 235^{\circ} \mathrm{C}, 608^{\circ} \mathrm{C}$ and $708^{\circ} \mathrm{C}$, respectively for Cat-CNH. The midrange reduction temperature peak $\left(235^{\circ} \mathrm{C}\right)$ is as a result of bulk $\mathrm{MoO}_{3}$ species present in the oxidic catalyst undergoing reduction in the presence of hydrogen to generate its tetrahedrally coordinated forms 
$\left(\mathrm{Mo}^{4+}\right)$, which are subsequently completely reduced to lower oxidation states. The absence of a peak occurring in the $340-360^{\circ} \mathrm{C}$ temperature range could also be noted; suggesting the sufficient reduction of bulk $\mathrm{CoO}_{3}$ species in the catalyst, giving indication of the probable formation of the Co-Mo-O phase, which forms the active phase for the HAS reaction. This observation is consistent with a previous study conducted by Surisetty et al. ${ }^{46}$ on a similar catalyst matrix supported on both activated carbon and MWCNT. One could also observe a small peak appearing around the region of $135^{\circ} \mathrm{C}$ from the TPR profile of Cat-CNH; which could be attributed to the reduction of rhodium species $\left(\mathrm{Rh}^{+1}\right)$ to its metallic forms $\left(\mathrm{Rh}^{\circ}\right)$. A similar observation has been reported in the literature. ${ }^{23}$ For the treated supported catalysts, similar peaks were observed to occur in the lower $\left(<200^{\circ} \mathrm{C}\right)$, middle $\left(200-400^{\circ} \mathrm{C}\right)$, and higher $\left(>400^{\circ} \mathrm{C}\right)$ temperature ranges, corresponding to the stepwise reduction of various molybdate species present in the catalysts. However, the positions of these peaks varied significantly with the different carbon material used for the catalyst formulation. As compared to Cat-OCP, the occurrence of a reduction peaks around $135^{\circ} \mathrm{C}$ for the Cats-CNH and $\mathrm{OCP}_{\mathrm{f}}$ suggests the complete reduction of $\mathrm{Rh}^{+1}$ to $\mathrm{Rh}^{\circ}$ species in these samples. ${ }^{46}$ Similarly, it could also be seen from that the first step reduction: $\mathrm{Mo}^{6+}$ to $\mathrm{Mo}^{4+}$ occurred at 280 and $315^{\circ} \mathrm{C}$ for Cats- $\mathrm{OCP}_{\mathrm{f}}$ and $\mathrm{OCP}$, respectively, which is higher than that observed for Cat-CNH. That notwithstanding, it should be noted that $\mathrm{Co}_{3} \mathrm{O}_{4}$ species have the same reduction temperature so there exists the possibility that the $\mathrm{H}_{2}$ consumption peak is an overlap contribution of multiple peaks corresponding to the reduction of $\mathrm{MoO}_{3}$ and $\mathrm{Co}_{3} \mathrm{O}_{4}$ species ${ }^{46}$ Furthermore, in the case of reduction of $\mathrm{Mo}^{4+}$ species to lower oxidation state oxo-molybdate species occurring at higher reduction temperatures, the observed trend followed the order: Cat$\mathrm{CNH}\left(608^{\circ} \mathrm{C}\right)<\mathrm{Cat}-\mathrm{OCP}_{\mathrm{f}}\left(652^{\circ} \mathrm{C}\right)<\mathrm{Cat}-\mathrm{OCP}\left(663^{\circ} \mathrm{C}\right)$. This trend can be explained by the fact that Cat-CNH possesses the highest surface area as compared to its counterparts; thus, dispersed metal species can adequately interact with the support; thus improving their reducibility and subsequent dispersion in the catalyst matrix as corroborated by XRD analysis.

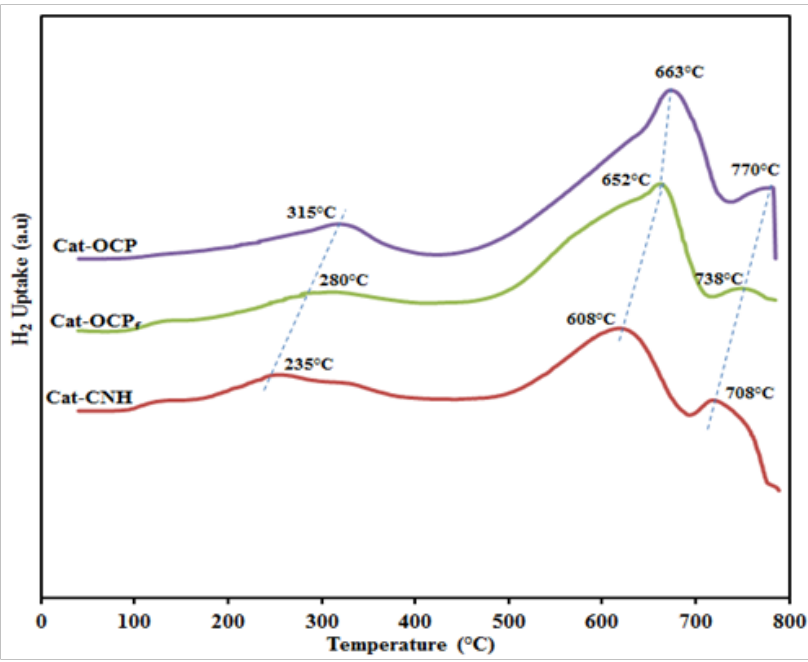

Figure 6 TPR profiles for $\mathrm{CNH}, \mathrm{OCP}_{f} \&$ OCP-supported $\mathrm{KCoRhMo} \mathrm{catalysts.}$

Transmission electron microscopic analysis: The TEM images of the pristine supports as well as the KCoRhMo catalysts were recorded and are presented in Figure 7. Common $\mathrm{CNHs}$ assemblies such as bud-like and dahlia-like CNHs were seen in the TEM images as shown in Figures 7a-7f. Aggregated CNHs size was within the range of 50-115 nm, which is consistent with published literature. It can also be observed from the TEM images of the pristine OCP and its supported catalyst Figure 7c, Figure $7 \mathrm{f}$ show a blend of $\mathrm{CNH}$ and other tube-like carbon morphologies. These were not observable in the $\mathrm{CNH}$ and $\mathrm{OCP}_{\mathrm{f}}$ counterparts; thus, suggesting that the OCP material could be a mixture of $\mathrm{CNH}$ and $\mathrm{CNT}$ which are known to have similar morphologies. Though the presence of nano-windows generated on the CNHs as a result of acid treatment was not clearly visible from the TEM images due to weak resolutions, the enhancement of surface area and pore volume of these samples as well as the nature of their isotherms is enough evidence of the occurrence of nano-windows in these samples. For the supported catalysts Figures 7d-7f, the presence of dark particle spots (which were absent in the pristine samples) suggests the incorporation of catalyst metal precursors into the various carbon matrix. As can be seen in Figure $7 \mathrm{~d}$, metal species were fairly dispersed following the co-impregnation step. However, not much homogeneous dispersion was observed for the $\mathrm{OCP}_{\mathrm{f}}$ and OCP-supported catalysts, probably due to their reduced surface areas as compared to its $\mathrm{CNH}$ counterpart.
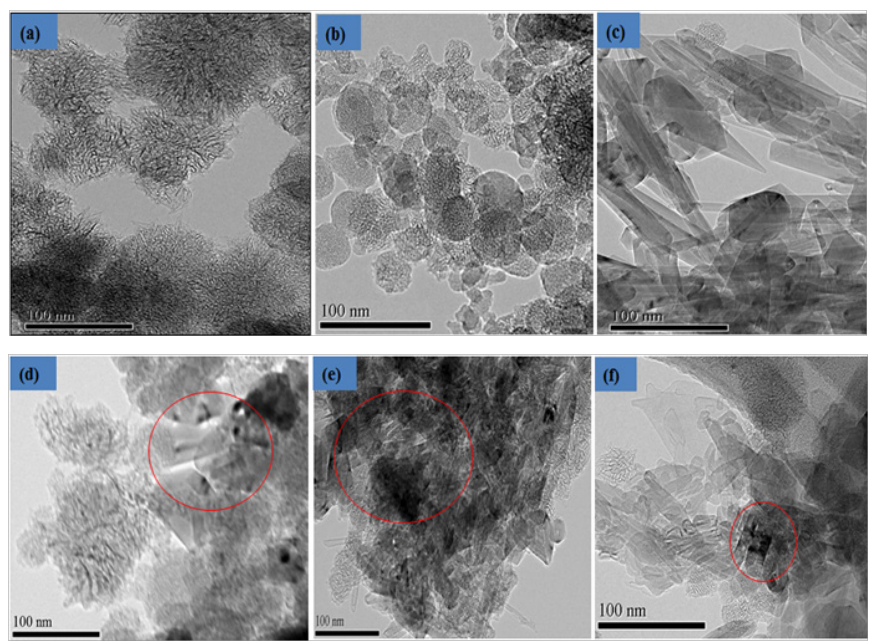

Figure 7 TEM images of KCoRhMo catalysts supported on: d) $\mathrm{CNH}$; (e) $\mathrm{OCP}_{f}$ and (f) OCP.

Catalytic performance tests of OMC-supported KCoMoRh Catalysts: The prepared catalyst samples were screened for their performance in the HAS reaction in a high-pressure fixed-bed micro reactor using syngas as feedstock under similar conditions of pressure, temperature, $\mathrm{H}_{2}$ : $\mathrm{CO}$, and GHSV of $8.3 \mathrm{MPa}, 300-340^{\circ} \mathrm{C}, 1.25$, and $3.6 \mathrm{~m}^{3}$ (STP) $/ \mathrm{kg}_{\text {cat }} \mathrm{h}$, respectively. The metals loading intended for the formulation of these catalyst samples were maintained the same to help study the influence of carbon $\left(\mathrm{CNH}, \mathrm{OCP}_{\mathrm{f}}\right.$ and $\left.\mathrm{OCP}\right)$-supported $\mathrm{KCoRhMo} \mathrm{catalysts} \mathrm{on} \mathrm{higher} \mathrm{alcohols} \mathrm{productivity.}$

Effect of temperature on $\mathrm{CO}$ conversion: Catalytic activities involving $\mathrm{MoS}_{2}$-supported catalysts are mostly at their peak performance at the onset of reaction and gradually decline as a result of time-on-stream due to the well-known phenomenon of initial precoking. ${ }^{25}$ Computation of the $\mathrm{CO}$ conversion was done for the catalysts following the attainment of stable catalytic activity, typically, after 18 $\mathrm{h}$ time-on-stream. ${ }^{7,11,21}$ As shown in Figure 8, CO conversion recorded for all the carbon-supported $\mathrm{KCoRhMo}$ catalysts increased as a function of temperature. It can be seen that increasing temperature from 330 to $340^{\circ} \mathrm{C}$ resulted in marginal increments in CO conversion. For the OCP-supported catalyst, $\mathrm{CO}$ conversion did not significantly 
increase with temperature from $310-340^{\circ} \mathrm{C}$; however, the converse is this case for Cat-CNH. For the latter catalyst, increasing temperature from 320 to $330^{\circ} \mathrm{C}$ resulted in $\sim 63 \%$ increment in $\mathrm{CO}$ conversion; giving an indication of the critical role temperature plays in the $\mathrm{CO}$ hydrogenation reaction. The recorded $\mathrm{CO}$ conversion at the highest temperature $340^{\circ} \mathrm{C}$ followed the trend: Cat-CNH $(52.4 \%)>$ Cat- $\mathrm{OCP}_{f}$ $(38.1 \%)>$ Cat-OCP $(25.4 \%)$. The observed trend can be attributed to the superior textural properties of the $\mathrm{CNH}$-supported catalyst as compared to its $\mathrm{OCP}_{\mathrm{f}}$ and $\mathrm{OCP}$ counterparts. Moreover, the higher surface area of Cat-CNH may have greatly enhanced the uniform distribution of the dispersed metal species as confirmed by XRD analysis. Furthermore, the less desirable textural properties of CatOCP may be responsible for its rather reduced catalytic activity as compared to its counterparts.

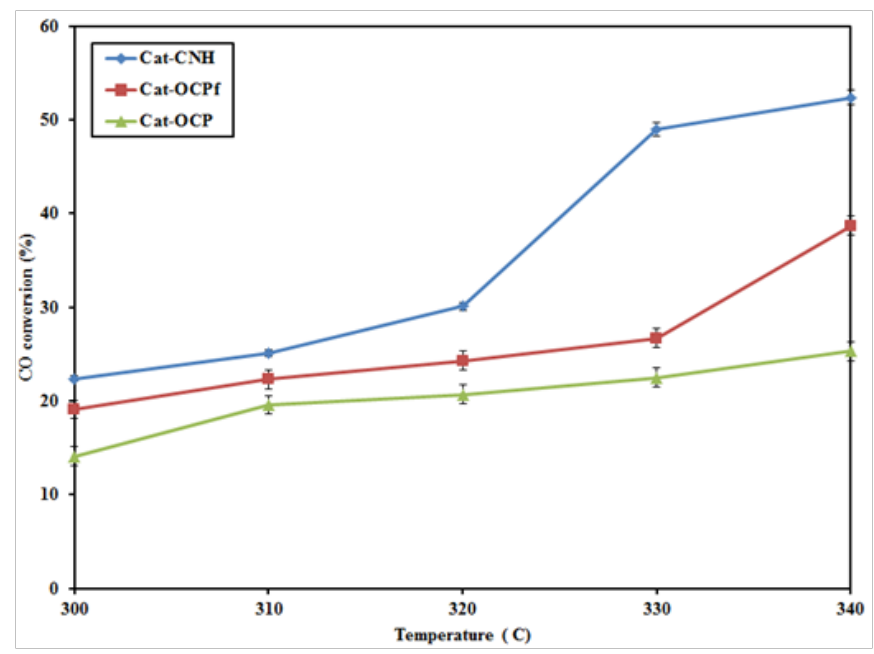

Figure $8 \mathrm{CO}$ conversion as a function of temperature for KCoMoRhsupported catalysts $\left(\mathrm{P}=1200 \mathrm{psi} ; \mathrm{T}=300-340^{\circ} \mathrm{C}\right.$; Catalyst $=2 \mathrm{~g} ; \mathrm{GHSV}=3600 \mathrm{~mL}$ (STP)/h g cat; $\left.\mathrm{H}_{2}: \mathrm{CO}=1.25\right)$.

\section{Alcohol products distribution for $\mathrm{CNH}, \mathrm{OCP} \&$ OCP- supported catalysts}

Catalytic performance of the oxidic form of the catalysts were evaluated in a high-pressure fixed-bed downward flow reactor system using syngas (molar composition: $50 \% \mathrm{H}_{2}: 40 \% \mathrm{CO}: 10 \% \mathrm{Ar}$ ) as the feedstock. Typical reaction conditions evaluated include pressure, temperature, and GHSV of $8.3 \mathrm{MPa}, 300-340^{\circ} \mathrm{C}$, and $3.6 \mathrm{~m}^{3}$ (STP)/ kgcat.h, respectively. An initial catalyst activation step was necessary prior to the onset of the HAS reaction to attain a more active sulfidic form of the catalyst. This was achieved by subjecting catalysts to an initial sulfidation/reduction step using a sulfiding gas mixture of $10 \% \mathrm{H}_{2} \mathrm{~S} / \mathrm{H}_{2}$ molar compositions. ${ }^{7,11,21}$ With the intended metals loading maintained constant for all four catalyst formulations, the influence of the different carbon $\left(\mathrm{CNH}, \mathrm{OCP}_{\mathrm{f}}\right.$, and $\left.\mathrm{OCP}\right)$ catalyst supports on the higher alcohols productivity was investigated.

The extent of alcohol products distribution is crucial and depends on the nature of supports employed for the HAS reaction, since the structure and morphology of the support would directly influence its porosity and the ease of modifying its surface chemistry via functionalization. This property of the supports can also affect its interaction with catalyst nanoparticles; thus, their capabilities of facilitating the dispersion of active metal species in the support matrix.

The alcohol composition as a function of carbon numbers for the supported catalysts has been presented in Figure 10. It is quite obvious that alcohol products stream generated by $\mathrm{CNH}, \mathrm{OCP}_{\mathrm{f}}$, and OCP-supported $\mathrm{KCoRhMo} \mathrm{catalysts} \mathrm{investigated} \mathrm{consisted} \mathrm{mostly} \mathrm{of}$ linear alcohols with carbon numbers in the range of $\mathrm{C}_{1}$ to $\mathrm{C}_{5}$. All the supported catalyst systems enhanced the production of these alcohols, mostly $\mathrm{C}_{2}$ alcohols, with selectivities of $45.1,43.8, \& 36.8 \%$ for Cat$\mathrm{CNH}, \mathrm{Cat}-\mathrm{OCP}_{\mathrm{f}}$ and Cat-OCP, respectively. Products selectivities for the gaseous and liquid streams of the $\mathrm{CO}$ hydrogenation reaction are summarized for all catalysts investigated and are presented in Table 2. As can be seen, Cats- $\mathrm{OCP}_{\mathrm{f}}$ and OCP tend to produce more $\mathrm{CO}_{2}$; suggesting their higher activity for the water-gas-shift reaction. Thus, from Figure 9 and Table 2, it becomes quite conclusive that all the supported $\mathrm{KCoRhMo} \mathrm{S}_{2}$ catalysts investigated for higher alcohol productivity turned out to have high selectivity towards the production of higher alcohols, with ethanol being the most predominant higher alcohol product in the final liquid product stream with the by-products comprising mainly $\mathrm{CO}_{2}$ and light hydrocarbons (methane and ethane).

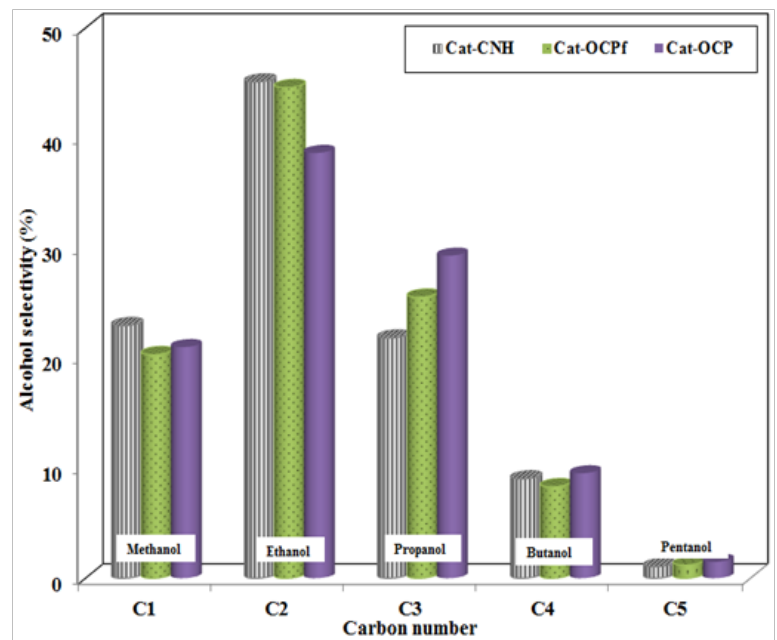

Figure 9 Alcohol composition as a function of carbon number $(\mathrm{P}=1200 \mathrm{psi}$; $\mathrm{T}=330^{\circ} \mathrm{C}$; Catalyst $\left.=2 \mathrm{~g} ; \mathrm{GHSV}=3600 \mathrm{~mL}(\mathrm{STP}) / \mathrm{h} \mathrm{g}_{\mathrm{cat}} ; \mathrm{H}_{2}: \mathrm{CO}=\mathrm{I} .25\right)$.

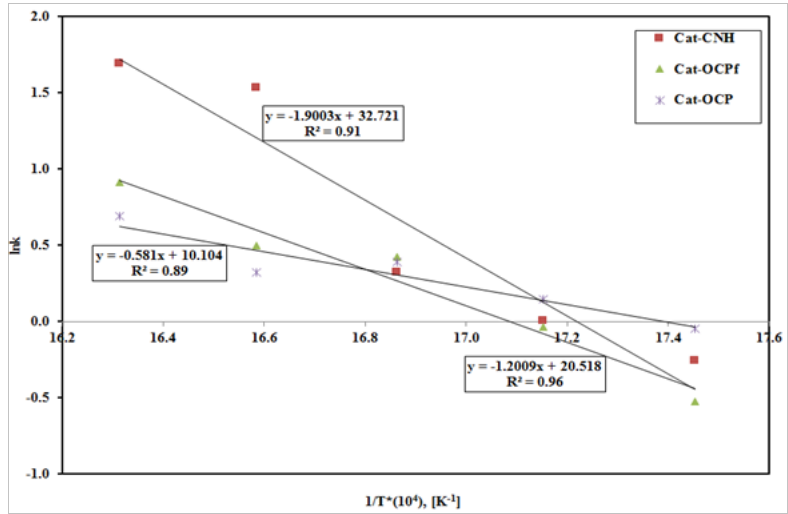

Figure 10 Arrhenius plot \& activation energy for $\mathrm{CNH}_{\mathrm{O}} \mathrm{OCP}_{\mathrm{f}}$ and $\mathrm{OCP}$ supported catalysts.

Arrhenius plot and activation energy calculations by the power law model: The energetics of three catalysts studied for the HAS reaction were evaluated and their respective apparent activation energies $\left(E_{a}\right)$ were computed by assuming a pseudo-first order for the higher alcohol reactions. To determine the activation energies and pre-exponential factors, a plot of lnk against $1 / T$ was computed and displayed in Figure 10. These parameters were determined from the Arrhenius plot for the rate constants and are summarized in Table 3. As can be seen by the profiles of the Arrhenius plots, increasing temperature resulted 
in increases in the rate constants, confirming the strong dependency of temperature in the HAS reaction. The apparent activation energies $\left(\mathrm{E}_{\mathrm{a}}, \mathrm{KJ} / \mathrm{mol}\right)$ computed within the range of temperatures studied (300$\left.340^{\circ} \mathrm{C}\right)$ followed the order: Cat-OCP $(157.9)>$ Cat $-O C P_{f}(99.8)>$ Cat$\mathrm{CNH}$ (48.3). This trend can be explained by the fact that the $\mathrm{CNH}$ had superior textural properties as compared to its $\mathrm{OCP}_{\mathrm{f}}$ and OCP counterparts; however, the enhanced textural properties of $\mathrm{CNH}$ supported catalysts did not only enhance its catalytic performance but also influenced the energetics as confirmed by the differences observed in apparent activation energies of the supports studied. By comparing the energetics of the catalysts investigated in the present study to that in the literature as depicted in Table 3 , the observed trend for activation energies followed the trend: Cat-CNH $>$ Cat-CNT $>$ Cat$\mathrm{OMC}>\mathrm{Cat}-\mathrm{OCP}_{\mathrm{f}}>\mathrm{Cat}-\mathrm{OCP}$. It can be concluded that at similar metals loading, the $\mathrm{CNH}$ and $\mathrm{OCP}_{\mathrm{f}}$-supported $\mathrm{KCoRhMo}$ catalysts can be promising for the conversion of syngas to higher alcohols.

Table 2 Products selectivities for $\mathrm{CNH}, \mathrm{OCP}_{\mathrm{f}}$ and $\mathrm{OCP}$-supported $\mathrm{KCoRhMo} \mathrm{catalysts} \mathrm{at} \mathrm{T}=330^{\circ} \mathrm{C}$

\begin{tabular}{|c|c|c|c|c|c|c|c|c|}
\hline \multirow[t]{3}{*}{ Catalyst } & \multicolumn{8}{|c|}{ Product selectivities (\%) } \\
\hline & \multicolumn{6}{|c|}{ Alcohol product selectivities (\%) } & \multicolumn{2}{|c|}{ Main by-products } \\
\hline & $c_{1}$ & $\mathrm{C}_{2}$ & $\mathrm{C}_{3}$ & $\mathrm{C}_{4}$ & $\mathrm{C}_{5}$ & Total alc. & Hydrocarbons & $\mathrm{CO}_{2}$ \\
\hline Cat-CNH & 21.1 & 40.6 & 23.2 & 7.1 & 0.9 & 92.9 & 3.2 & 2.4 \\
\hline Cat-OCP $P_{f}$ & 16.5 & 30.2 & 18.3 & 4.3 & 0.8 & 70.1 & 10.2 & 16.8 \\
\hline Cat-OCP & 14.5 & 20.1 & 16.5 & 2.7 & 0.7 & 54.6 & 16.1 & 26.5 \\
\hline
\end{tabular}

Table 3 Activation energies comparison for carbon-supported KCoRhMo catalysts for the HAS reaction

\begin{tabular}{|c|c|c|}
\hline Catalyst & Activation energy, $\mathrm{Ea}(\mathrm{KJ} / \mathrm{mol})$ & Reference \\
\hline Cat-CNH & 48.3 & Present work \\
\hline Cat-OCP & 99.8 & Present work \\
\hline Cat-OCP & 157.9 & Present work \\
\hline KCoRhMo/OMC & 86.4 & Boahene et al. ${ }^{21}$ \\
\hline KCoRhMo/MWCNT & 72.4 & Boahene et al. ${ }^{21}$ \\
\hline *CoMoK-10\%CNT & 74.3 & Ma et al..$^{17}$ \\
\hline
\end{tabular}

\section{Conclusion}

In summary, $\mathrm{CNH}$ support and its by-products $\left(\mathrm{OCP}_{\mathrm{f}}\right.$ and $\left.\mathrm{OCP}\right)$ were synthesized by the submerged arc discharge in liquid nitrogen technique, functionalized with $30 \mathrm{wt} . \%$ nitric acid under reflux conditions, and employed in the formulation of K-doped $\mathrm{CoRhMoS}_{2}$ catalysts for HAS applications. All catalysts prepared using these novel supports showed activity towards higher alcohols via the $\mathrm{CO}$ hydrogenation route. At similar metals loading, BET analysis of all catalysts evidenced significant structural mesoporosity and orderliness since the physical properties of the materials were not compromised; however, a significant blockage was observed in Cat$\mathrm{OCP}$ as confirmed by the $\mathrm{NS}_{\mathrm{BET}}$ computations. Moreover, at similar metals loadings of $9 \% \mathrm{~K}, 4.5 \% \mathrm{Co}, 15 \% \mathrm{Mo}$ and $1.5 \mathrm{wt} . \% \mathrm{Rh}, \mathrm{XRD}$ analysis evidenced a better metal nanoparticles dispersion on Cat$\mathrm{CNH}$ since less crystalline peaks were detected as confirmed by the TEM images. At the optimum temperature $330^{\circ} \mathrm{C}$, linear alcohols were produced with the trend of $\mathrm{C}_{2+}$ alcohols selectivities following the order: Cat-CNH (63.7) $>$ Cat-OCP $\quad$ (48.9) $>$ Cat-OCP (38.2). Finally, within the range of temperatures studied $\left(300-340^{\circ} \mathrm{C}\right)$, the calculated apparent activation energy, $(\mathrm{E}, \mathrm{KJ} / \mathrm{mol})$, for the catalysts followed the order: Cat-OCP (157.9) $>$ Cat-OCP ${ }_{f}(99.8)>$ Cat-CNH (48.3), corroborating the superior catalytic performance of the $\mathrm{CNH}-$ supported catalysts as compared to its $\mathrm{OCP}_{\mathrm{f}}$ and $\mathrm{OCP}$ counterparts. The results of this study provide insight to elucidate the crucial role different carbon materials play as catalyst support in their application for higher alcohol synthesis.

\section{Acknowledgements}

The authors acknowledge BioFuel Net Canada, Canada Research Chair Program, and the Natural Science and Engineering Research Council of Canada for financing this research.

\section{Conflict of interest}

The author declares no conflict of interest.

\section{References}

1. Geidl J, Walton $\mathrm{H}$, Mayes $\mathrm{F}$, et al. Alternatives to Traditional Transportation Fuels:An Overview. DOE/EIA-0585/O. 1994.

2. Nylund NO, Aakko Saksa P, Sipilä K. VTT Research Notes. 2008. 2426.

3. Surisetty VR. Ph.D Thesis, submitted to the University of Saskatchewan. Canada, 2010. p. 30-35.

4. Filikov AV, Myasoedov NF. Hydrogen spillover and the rate of heterogeneous catalytic hydrogenation. Quantitative model. J Phys Chem. 1986;90(21):4915-4916

5. Tauster SJ, Fung SC, Baker RTK, et al. Strong interactions in supportedmetal catalysts Science. 1981;211:1121-1125.

6. Hindermann JP, Deluzarche A, Kieffer R, et al. Characterization of chemisorbed species in $\mathrm{CO} / \mathrm{H}_{2}$ and $\mathrm{CO}_{2} / \mathrm{H}_{2}$ reactions. Evolutive behaviour of the species. Can J Chem Eng. 1983;61(1):20-28.

7. Boahene PE, Sammynaiken R, Dalai AK. Fischer-Tropsch Synthesis. Catalysts and Catalysis. 2016;15:275-294. 
8. Ryndin YA, Hicks RF, Bell AT. Effects of metal-support interactions on the synthesis of methanol over palladium. J Catal. 1981;70(2):287-297.

9. Concha BE, Bartholomew GL, Bartholomew $\mathrm{CH}$. $\mathrm{CO}$ hydrogenation on supported molybdenum catalysts:Effects of support on specific activities of reduced and sulfided catalysts. J Catal. 1984;89:536-541.

10. Iranmahboob J, Hill DO. Oxidative dimerisation of methane on supported palladium oxide catalysts. Catal Lett. 2002;4(1):49-55.

11. Surisetty VR, Tavasoli A, Dalai AK. Influence of porous characteristics of the carbon support on alkali-modified trimetallic $\mathrm{Co}-\mathrm{Rh}-\mathrm{Mo}$ sulfided catalysts for higher alcohols synthesis from synthesis gas. Appl Catal A 2011;393(1-2):50-58.

12. Iijima S, Yudasaka M, Yamada R, et al. Nano-aggregates of single-walled graphitic carbon nano-horns. Chem Phys Lett. 1999;309(3-4):165-170.

13. Kasuya D, Yudasaka M, Takahashi K, et al. Selective Production of Single-Wall Carbon Nanohorn Aggregates and Their Formation Mechanism. J Phys Chem B. 2002;106(19):4947-4951.

14. Azami T, Kasuya D, Yuge R, et al. Large-Scale Production of Single-Wal Carbon Nanohorns with High Purity. J Phys Chem C. 2008;112(5):1330 1334.

15. Yudasaka M, Iijima S. In Carbon Nanotubes:Advanced Topics in the Synthesis, Structure, Properties and Applications. In: editors, Topics Applied Physic. Heidelberg, Germany, 2008. 111:605-629.

16. Bekyarova E, Hashimoto A, Yudasaka M, et al. Palladium Nanoclusters Deposited on Single-Walled Carbon Nanohorns. J Phys Chem B 2005;109(9):3711-3714.

17. Urita K, Seki S, Utsumi S, et al. Effects of Gas Adsorption on the Electrical Conductivity of Single-Wall Carbon Nanohorns. Nano Letters 2006;6(7):1325-1328.

18. Utsumi S, Urita K, Kanoh H, et al. Preparing a Magnetically Responsive Single-Wall Carbon Nanohorn Colloid by Anchoring Magnetite Nanoparticles. J Phys Chem B. 2006;110(14):7165- 7170.

19. Aryee E, Dalai AK, Adjaye J. Functionalization and Characterization of Carbon Nanohorns (CNHs) for Hydrotreating of Gas Oils. Top Catal. 2014;57(6):796-805.

20. Wang H, Chhowalla M, Sano N, et al. Large-scale synthesis of single-walled carbon nanohorns by submerged arc. Nanotechnology. 2004;15(5):546-550

21. Boahene PE, Surisetty VR, Sammynaiken R, et al. Higher Alcohol Synthesis Using K-Doped $\mathrm{CoRhMoS}_{2} / \mathrm{MWCNT}$ Catalysts:Influence of Pelletization, Particle Size and Incorporation of Binders. Top Catal. 2014;57(6):538-549.

22. Khodakov AY, Griboval A, Bechara R, et al. Pore-Size Control of Cobalt Dispersion and Reducibility in Mesoporous Silicas. $J$ Phys Chem B 2001;105(40):9805-9811.

23. Murata K, Kaneko K, Kokai F, et al. (2000) Hydrogen production from methane and water at low temperature using EuPt supported on singlewall carbon nanohorns. Chem Phy Lett. 2000;331:14-20.

24. Murata K, Kaneko K, Steele WA, et al. Nano Letters. 2001;1(7):197-199.

25. Sigurdson SK. Thesis, University of Saskatchewan, Saskatoon. Canada, 2010

26. Vradman L, Landau MV, Kantorovich D, et al. Evaluation of metal oxide phase assembling mode inside the nanotubular pores of mesostructured silica. Micropor Mesopor Mater. 2005;70(1-3):307-318.

27. Zhao Z, Dai Y, Lin J, et al. Highly-Ordered Mesoporous Carbon Nitride with Ultrahigh Surface Area and Pore Volume as a Superior Dehydrogenation Catalyst. Chem Mater. 2014;26(10):3151-3161.
28. Calafata A, Vivas F, Brito JL. Effects of phase composition and of potassium promotion on cobalt molybdate catalysts for the synthesis of alcohols from $\mathrm{CO}_{2}$ and $\mathrm{H}_{2}$. Appl Catal A Gen. 1998;172(2):217-224.

29. Wang K, Zhang L. Synthesis of Ordered Mesoporous Carbon and Its Electrochemical Performances. Int J Electrochem Sci. 2013;8:28922897.

30. Surisetty VR, Tavasoli A, Dalai AK. Synthesis of higher alcohols from syngas over alkali promoted $\mathrm{MoS}_{2}$ catalysts supported on multi-walled carbon nanotubes. Appl Catal A Gen. 2009;365(2):243-251.

31. Haber J, Block JH, Delmon B. Manual of methods and procedures for catalyst characterization (Technical Report). Pure \& Appl Chem. 1995;67(8-9):1257-1306.

32. Schwan J, Ulrich S, Batori V, et al. Raman spectroscopy on amorphous carbon films. J Appl Phys. 2001;80(1):440-447.

33. Yang W, Alsmeyer DC, Mc Creery RL. Raman spectroscopy of carbon materials:structural basis of observed spectra. Chem Mater. 1990;2(5):557-563.

34. Xiong H, Jewell LL, Coville NJ. Shaped Carbons As Supports for the Catalytic Conversion of Syngas to Clean Fuels. ACS Catal. 2015;5(4):2640-2658.

35. Shimodaira N, Masui A. J Appl Phys. 2002;902-909.

36. Vinu A, Srinivasu P, Takahashi M, et al. Controlling the textura parameters of mesoporous carbon materials. Micropor Mesopor Mater. 2007;100:20-26.

37. Teng L, Tang T. IR study on surface chemical properties of catalytic grown carbon nanotubes and nanofibers. J Zhejiang Univ Sci A. 2008;9(5):720-726.

38. Xiao B, Thomas K. Competitive Adsorption of Aqueous Metal Ions on an Oxidized Nanoporous Activated Carbon. Langmuir. 2004. 20(11):45664578 .

39. Bazula PA, Lu AH, Nitz JJ, et al. Surface and pore structure modification of ordered mesoporous carbons via a chemical oxidation approach. Micro \& Meso Mater. 2008;108(1-3):266-275.

40. Lazaro MJ, Calvillo L, Bordeje EG, et al. Functionalization of ordered mesoporous carbons synthesized with SBA-15 silica as template. Micropor Mesoporous Mat. 2007;103(1-3):158-165.

41. Serp P, Machado B. Carbon Nano materials for Catalysis, in Nano structured Carbon Materials for Catalysis. 2015;1-45.

42. Otake Y, Jenkins RG. Characterization of oxygen-containing surface complexes created on a microporous carbon by air and nitric acid treatment. Carbon. 1993:31(1):109-121.

43. Cheng PZ, Teng H. Electrochemical responses from surface oxides present on $\mathrm{HNO}_{3}$-treated carbons. Carbon. 2003;41(11):2057-2063.

44. Teng H, Suuberg EM. Chemisorption of nitric oxide on char. 1. Reversible nitric oxide sorption. J Phys Chem. 1993;97(2):478-483.

45. Surisetty VR, Dalai AK, Kozinski. Alkali-Promoted Trimetallic CoRh-Mo Sulfide Catalysts for Higher Alcohols Synthesis from Synthesis Gas:Comparison of MWCNT and Activated Carbon Supports. J Ind Eng Chem Res. 2010;49(15):6956-6963.

46. Arnoldy $\mathrm{P}$, Moulijn JA. Temperature-programmed reduction of CoOAI2O3 catalysts. J Catal. 1985;93(1):38-54. 